\title{
ESTIMATION OF LEACHATE FROM A PILOT SCALE LYSIMETER
}

\author{
${ }^{1}$ Dinesh Raj Manandhar*, ${ }^{2}$ William Hogland, ${ }^{3}$ V. Krishnamurthy, ${ }^{1}$ Sanjay Nath Khanal \\ ${ }^{1}$ Department of Environmental Science and Engineering, School of Science, \\ Kathmandu University, Nepal \\ ${ }^{2}$ Environmental Engineering and Recovery, The School of Natural Sciences, \\ Linnaeus University, SE-391 82 Kalmar, Sweden \\ ${ }^{3}$ Department of Biotechnology, PES Institute of Technology, 100 Ft. Ring Road, BSK III \\ Stage, Bangalore-560 085, India \\ *Corresponding address: dineshmanandhar@ gmail.com \\ Received 02 July, 2012; Revised 29 October, 2012
}

\begin{abstract}
The most important component of solid waste management is long-term safe and reliable disposal of solid waste in sanitary landfills. Leachate formed in landfills needs proper management. The biodegradable portion of waste is largely responsible for the production of leachate and landfill gas. This paper presents the outcome of the research on the water management of landfill in Nepal using a designed and built pilot scale field lysimeter model. The leachate production from the lysimeter as an effect of climatological factors is assessed. The Hydrologic Evaluation of Landfill Performance (HELP) model is used to compute estimates of water balances. Simulation of the model indicates that the evapotranspiration (ET) is nearly constant and do not follow the precipitation and percolation trend. Also the evapotranspiration component in this case, is not high. This may be due to the small surface area of lysimeter and larger portion of the leachate percolated before evaporation could take place. The model has been calibrated for the local situation with the limited observed data of leachate generation from the lysimeter. However the trend of leachate generation on HELP simulation and Actual Data seem to be similar during month of October to December season, but during June to September, the trend shows higher actual percolation rate compared to the model output. This may be due to the higher value of permeability of barrier soil (in the range of $10^{-5} \mathrm{~cm} / \mathrm{s}$ ), which should be generally in the range of $10^{-7} \mathrm{~cm} / \mathrm{s} \mathrm{or}$ lower. The rainy season during June to September may be another reason, when soil is wet most of the time. The annual data shows that percolation is about $81-84 \%$ of precipitation amount, whereas evapotranspiration is about $15-19 \%$. The application of the model may be a valuable tool to determine strengths and weaknesses of designing and operating of landfills in developing countries like Nepal.
\end{abstract}

Keywords: Evapotranspiration, HELP Model, Landfill Leachate, Solid Waste, Water Balance

\section{INTRODUCTION}

Over $95 \%$ of the waste produced in developing countries is disposed off in landfills; open dumps, on riverbanks, directly into the sea, or openly burnt because of insufficient waste collection and final disposal systems. Meanwhile as Europe and industrialized countries go for sophisticated technologies and solutions (e.g. modern incineration and waste to energy technologies) there is still a huge demand for proper landfilling in developing countries. Facing the accelerated generation of solid waste caused by increasing population, migration from country side, urbanization, and industrialization, the problem has become one of the primary environmental issues in low and middle income Asian countries [1]. Especially in developing countries like Nepal, landfilling is considered to be a reliable and cost effective method if adequate land is available. However, improper management and operation of landfill is creating a severe environmental impact such as surface and subsurface water pollution and obnoxious odor. This is basically due to improper operation and management of landfills, especially regarding leachate and landfill gas management. Uncontrolled disposal of Municipal Solid Waste (MSW) causes considerable environmental pollution besides being directly harmful to public health. Rivers in the Kathmandu city have been seriously polluted by discharges of untreated industrial and domestic solid waste. Improvement practices have 
been attempted in the waste management sector for more than twenty years in Kathmandu Metropolitan City. After the closure of Gokarna landfill in the year 2000 and continued use of Sisdole Landfill since 2005 till date, making availability of landfill site and improved operations of waste management facility are the Kathmandu's most pressing issues.

Lands and rivers are contaminated from improper disposal practices in and around Kathmandu city and they continue to impact public health, environmental quality, and land values. The cost to clean up these contaminated sites will always be significantly higher than the cost incurred to dispose off the waste properly and management of landfills. To prevent the water resources from further pollution, the leachate management and control system need to be in place in landfills.

Leachate may be defined as a liquid that has percolated through solid waste and has extracted dissolved or suspended materials. In most landfills, leachate is composed of liquid that has entered the landfill from external sources, such as precipitation, surface drainage, and groundwater and the liquid produced from the decomposition of waste. The organic, inorganic and biological contaminants in the waste get solved in leachate. By studying water balance of the landfill, the potential for formation of leachate can be assessed. The need to understand and control leachate production at landfill sites is not a new phenomenon but it has perhaps become a more significant consideration during the last few decades. Leachate management is a dire need to control surface and subsurface pollutions. For proper management, leachate quantity as well as quality aspect need to be given attention and properly planned [2]. This will help the landfill management agencies such as municipalities, private companies and other organizations to develop advanced as well as local natural technologies that could be utilized.

\section{OBJECTIVE AND SCOPE}

This research aims to estimate water balance for landfill on quantitative basis using a pilot scale Landfill Lysimeter Model in Nepal. The main objective of this research is to have estimation of water balance on quantitative basis for designing and operating landfills in developing countries with different climatic conditions. The research focuses particularly on the leachate production in a landfill. The use of computer software like Hydrological Evaluation of Landfill Performance, HELP model [3] will be tested in Nepalese context. The outcome of the research work will be beneficial in addressing waste management issues especially landfill design and operational aspects in Nepalese context. Water management is governed by water input and output from landfill. Consideration and general conclusions shall be drawn from a research work using pilot scale lysimeter in Nepal, which serves as a case study for better understanding [4].

\section{WATER BALANCE AND APPLICATION OF MODEL}

The quantity of leachate that could be generated from a landfill can be predicted by performing a water balance. A water balance involves an accounting of liquid flows into and out of the landfill system, and of liquid stored within the system. In most landfills, the significant inflows are precipitation and water contained in the delivered waste. The significant outflow is leachate. Following is an approach that can be used to obtain an approximation of the quantity of percolation that can be expected in a landfill by a conventional hydrological water balance from equation (1) as shown below [5]. 
$L=P-R-E T-\Delta S$

$P=\quad$ Quantity of net precipitation per unit area $(\mathrm{mm})$

$R=\quad$ Quantity of runoff per unit area $(\mathrm{mm})$

$E T=$ Quantity of moisture lost through evapotranspiration per unit area $(\mathrm{mm})$,

$\Delta S=$ Change in the amount of moisture stored in a unit volume of landfill $(\mathrm{mm})$

$L=\quad$ Quantity of percolation through the cover per unit area of soil cover (mm)

The total amount of moisture that can be stored in a unit volume of soil is a function of two variables; the field capacity (FC) and the permanent wilting percentage (PWP). For this research, HELP, a US EPA water balance model, has been applied [3]. The Visual HELP model, a window based software has been used for testing the effectiveness of landfill designs, and specific factors influencing the water balance at site. The following data were used as input:

- Weather parameters such as precipitation, solar radiation, temperature, evapotranspiration. Data of meteorological stations at Kathmandu University, Dhulikhel have been utilized. The required set of data over the period from 2000 until 2004 has been analyzed. These years sufficiently characterize the broad range of annual precipitation $(1417-2228 \mathrm{~mm})$.

- Soil properties (porosity, field capacity, wilting point, and saturated hydraulic conductivity) are determined in the laboratory. Default values of waste properties from the HELP model have been used.

- Landfill design data such as liners, leachate collection systems, surface slope, slope length and area of landfill are the inbuilt data of pilot scale lysimeter.

\section{MATERIALS AND METHODOLOGY}

This research has been carried out for the first time in Nepal. Lysimeter model already researched under Asian Regional Research Programme on Environmental Technology (ARRPET), a project on Sustainable Solid Waste Landfill Management in Asia supported by Swedish International Development Agency (SIDA) coordinated by Asian Institute of Technology (AIT), Bangkok Thailand [6] have been taken as reference. This research has been carried out by installation of a landfill lysimeter model made from Reinforced Cement Concrete (RCC) rings with $1 \mathrm{~m}$ diameter and $3 \mathrm{~m}$ height (Fig. 1). A barrier soil layer of $0.3 \mathrm{~m}$ thick has been placed at the bottom. The drainage system (aggregates chip size between $5 \mathrm{~mm}-10 \mathrm{~mm}$ ) of $0.5 \mathrm{~m}$ thickness has been placed above the barrier soil. The leachate from the lysimeter is drained towards two storage units ( 2 numbers of plastic buckets each with a capacity of 17 litres), one draining out from drainage layer and other from barrier soil layer at bottom. The leachate measurements were taken on daily basis.

Channeling of leachate was provisioned through perforated PVC pipe of $25 \mathrm{~mm}$ diameter installed on the drainage layer. For this two HDPE pipes were provisioned from drainage and barrier soil layer respectively. Solid waste was received from a local transfer station and was placed inside the lysimeter at the rate of 200 to $250 \mathrm{~mm}$ thick each time. The waste was compacted to the density of about $600 \mathrm{~kg} / \mathrm{m}^{3}$ until total height of $1.8 \mathrm{~m}$ was reached. Clay loam layer of $300 \mathrm{~mm}$ thickness was placed as the cover soil layer. The lysimeter has been installed in a way that it models a landfill. 


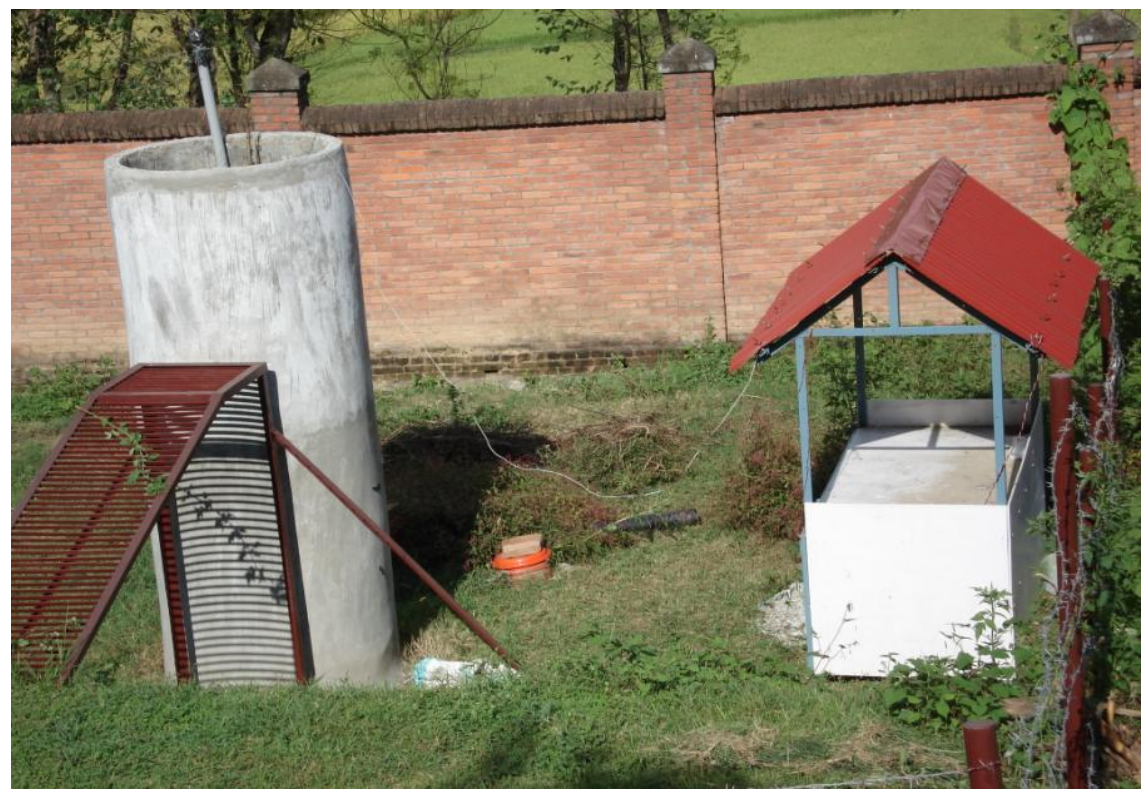

Figure 1 Pilot Scale Lysimeter

The physical parameters, organic constituents, inorganic constituents and biological parameters of wastes were analyzed. Only the quantitative part has been discussed in this paper. The required tests for soil parameters like Saturated hydraulic conductivity, Total porosity, Field capacity and Permanent wilting percentage have been carried out at laboratory scale. However, some of these waste parameters have been taken from HELP model default value as mentioned above. Data were input in to the model and simulations were run using Visual HELP Software and data analyzed.

\section{RESULTS AND DISCUSSIONS}

Fig. 2 below shows the outcome of the simulation using monthly averages data. It indicates that the evapotranspiration (ET), which is an output from the HELP model is nearly constant and do not follow the rainfall and percolation trend. The method used in the HELP program [3] for computing evapotranspiration uses the concept of potential evapotranspiration as the basis for prediction of the surface and soil water evaporation and the plant transpiration components. The term "potential evapotranspiration" refers to the maximum quantity of evaporation rate that the atmosphere may extract from a plot in a day. A modified Penman (1963) equation as shown in equation (2) is used to calculate the energy available for evapotranspiration.

$$
L E i=P E N R i+P E N A i
$$

$\mathrm{LE}=$ energy available on day $i$ for potential evapotranspiration in the absence of a snow cover, langleys

$\mathrm{PENR}_{\mathrm{i}}=$ radiative component of the Penman equation on day $\mathrm{i}$, langleys

$\mathrm{PENA}_{\mathrm{i}}=$ aerodynamic component of the Penman equation on day $\mathrm{i}$, langleys

These two components are calculated as in following equations: 


$$
\begin{aligned}
& \text { PENRi }=\frac{\Delta i}{\Delta i+\gamma} R n i \\
& \text { PENAi }=\frac{15.36 \gamma}{(\Delta i+\gamma)}(1+0.1488 \mu)(e o i-e a i)
\end{aligned}
$$

$\mathbf{R}_{\mathbf{n i}}=$ net radiation received by the surface on day $\mathrm{i}$, langleys

$\Delta_{i}=$ slope of the saturation vapor pressure curve at mean air temperature on day $i$, millibars per ${ }^{\circ} \mathrm{C}$

$\gamma=$ constant of the wet and dry bulb psychrometer equation, assumed to be constant at 0.68 millibars per ${ }^{\circ} \mathrm{C}$

$\mu=$ wind speed at a height of 2 meters, in kilometers/hour (average annual wind speed used in model)

$\mathbf{e}_{\mathbf{i}}=$ saturation vapor pressure at mean air temperature on day i, millibars

$\mathbf{e}_{\mathbf{a}}=$ mean vapor pressure of the atmosphere on day $\mathrm{i}$, millibars

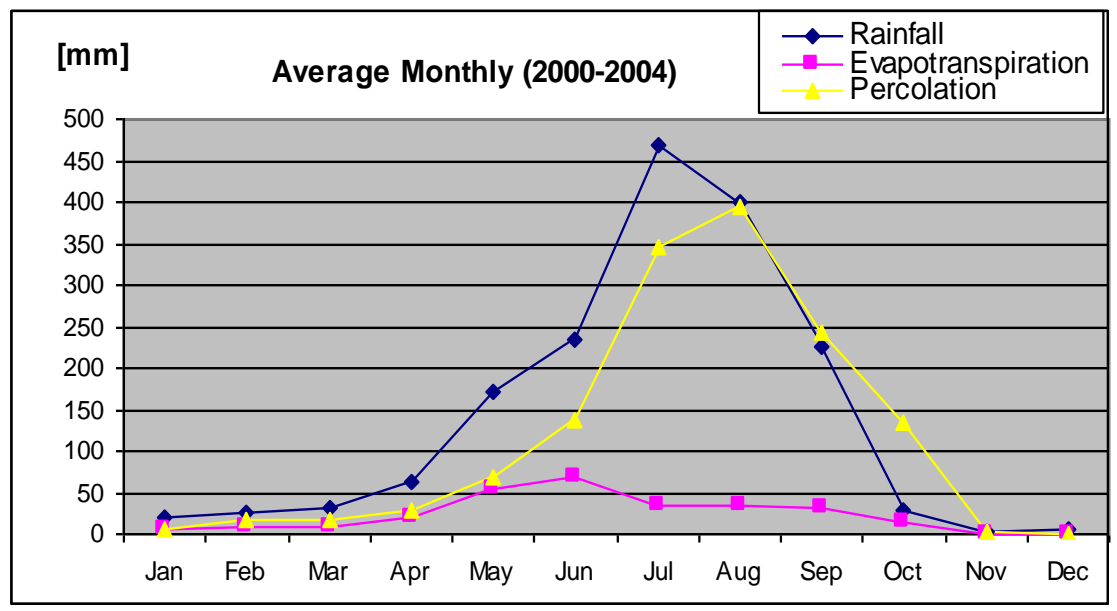

Figure 2 Monthly average of Rainfall, ET and Percolation

The runoff value is assumed zero. Solar radiation, a parameter dependent upon the temperature and sunshine duration hours, has an impact upon the evapotranspiration. The solar radiation distribution over a year has shown that even during the wet season, the intensive solar radiation will have a strong effect on evapotranspiration. The evapotranspiration, in this case, is not high, may be due to the small area of lysimeter and major portion has been percolated before evaporation and transpiration could take place. However, during the dry season the potential evaporation is non attainable.

The 5 yearly data (Fig. 3) also indicates that evapotranspiration seems to be almost constant and percolation is following the trend of rainfall and it is a dependent parameter. The evapotranspiration is not dependent on rainfall. There is an immediate response of percolation after rainfall. The input here is only rainfall. The moisture content of waste, which is generally negligible compared to the rainfall, has not been considered in the calculation. The annual data shows percolation is about $81-84 \%$ of rainfall amount whereas evapotranspiration is only about $15-19 \%$. On daily basis, however the percentage response may be different depending on rainfall for consecutive number of days. The response of rainfall as percolation is observed after few days, so the percentage is even more than the 
rainfall amount on the same day. When aggregated in weeks, months or annual, it is different than daily basis.

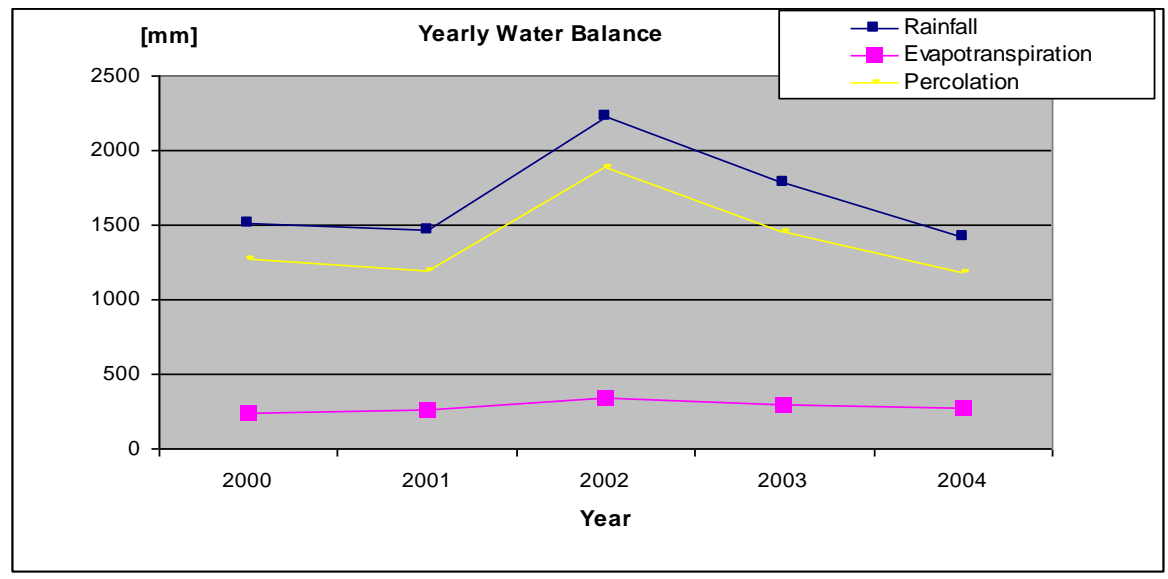

Figure 3 Annual Data of Rainfall ET and Percolation

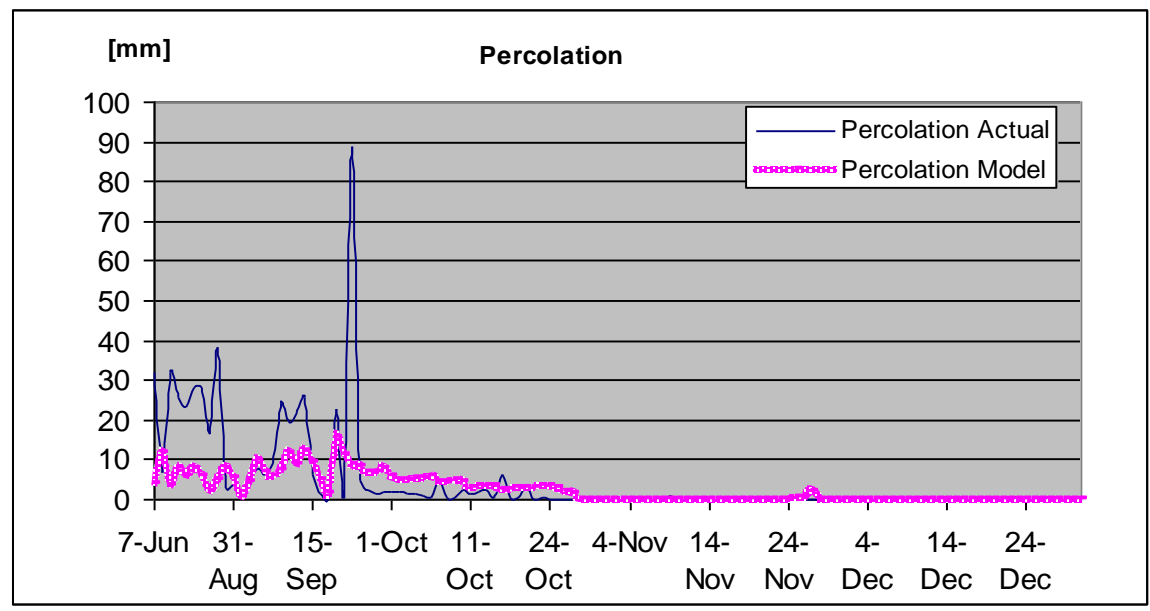

Figure 4 Percolation related to Model and Actual

The daily rate of percolation is about 3.47 liters $/ \mathrm{m}^{2} /$ day on an average, which is generally high. Although in the view of highest rainfall days during 2000 to 2004 the average highest rainfall is 88 litre $/ \mathrm{m}^{2} /$ day and percolation is about 5.78 liters $/ \mathrm{m}^{2} /$ day on an average (only about $6.5 \%$ of the rainfall). These conditions are best characterized by a season of high intensity rainfall (up to $220 \mathrm{~mm}$ /day and above in Dhulikhel). However, it has been observed that 215-269 days per year showed up with no rainfall and there is a distinct arid period.

The evapotranspiration component as shown in above equation of the water balance might have been underestimated, as it is dependent on solar radiation, vegetative growth (hardly any), evaporative zone depth, wind speed, and relative humidity [3]. These parameters need to be studied in detail and should represent the local conditions to give better results for the model. The model has been calibrated for the local situation with the limited observed data of leachate generation from the lysimeter. However the trend of leachate generation on HELP simulation and actual data seem to be similar in October to December season, but in June to September, the trend shows larger percolation rate in actual data than model (Fig. 4). This may be due to the higher value (in the range of $10^{-5} \mathrm{~cm} / \mathrm{s}$ ) of hydraulic conductivity of barrier 
soil, which should be generally in the range of $10^{-8} \mathrm{~cm} / \mathrm{s}$. Also it may be due to the rainy season (June-September) when soil is wet at most of the time. This research is yet to fully discuss the variation of percolation, it may be linked with soil properties and is a matter of further research. Furthermore, the parameters such as landfill design criteria (layer data: hydraulic conductivity or slope) and operation processes of landfill have to be investigated further.

\section{CONCLUSIONS}

The application of the HELP model in the country like Nepal where monsoon season concentrate from June to September has raised issue like impact on water balance by the large variation of short-term rainfall, which might have greater input into percolation. Nevertheless the trend for the water balance has been predicted based upon the 5-year climatic data. This research has raised some issues regarding water management and its solutions towards proper management of landfills and other influencing parameters to be investigated in detail. The application of the model may be taken as a valuable tool to determine strengths and weaknesses for designing and operating of landfills in developing countries like Nepal. Landfill hydrology is an important issue to be investigated since most Asian landfills are located in regions with monsoon climate, where extremely high precipitation for few months followed by dry season with high evaporation.

The use of lysimeter is to study behavior or hydrology of leachate generation and the characteristics of leachate production. Thus the results should serve other purposes as well like designing leachate collection systems and landfill design.

\section{ACKNOWLEDGEMENTS}

The authors would like to express sincere gratitude to International Foundation of Science (IFS), Sweden for providing grant for the research work and would like to express appreciation to the Kathmandu University for providing space and continued support for the research.

\section{REFERENCES}

[1] Hogland, W, Visvanathan, C, Marques, M \& Manandhar D R, Landfill in Asia, Improving Sanitation of Landfill Sites, Waste Management World, Review Issue (2005-2006) 87.

[2] Tränkler J, Manandhar D R, Xiaoning Q, Sivaporn-pun V \& Schöll W, Effects of Monsooning Conditions on the Management of Landfill Leachate in Tropical Countries, Proceedings Sardinia 01, Eighth International Waste management and Landfill Symposium, Pula, Cagliari, Italy, Vol II, (2001)59.

[3] Schroeder P R, Dozier T S, Zappi P A, McEnroe B M, Sjostrom J W \& Peyton R L, The Hydrologic Evaluation of Landfill Performance (HELP) Model: Engineering Documentation for Version 3, EPA/600/R-94/168b, September 1994, U. S. Environmental Protection Agency Office of Research and Development, Washington, DC (1994).

[4] Manandhar D R, Krishnamurthy V \& Kasaju Y, "Quantitative Leachate Estimation from a Pilot Scale Lysimeter Study” Int. J. Environment and Pollution, 26 (4) (2007). 
[5] Manandhar D \& Tränkler J, Water Management of Landfills in Tropical Countries, Proceedings of the 12th Congress of the Asia and pacific Division of the International Association for Hydraulic Engineering and Research, Bangkok, 4(2000)1341.

[6] Visvanathan C, Tränkler J, Kuruparan, P \& Xiaoning Q, Influence of Landfill Operation and Waste Composition on Leachate Control- Lysimeter Experiments under Tropical Conditions, 2nd Asia Pacific Landfill Symposium in Seoul, Korea, Sep 25-28 (2002). 